\title{
Shorter Is Better: Findings of a Bite-Size Mobile Learning' Pilot Project
}

\author{
Jacques van der Meer, David Berg, Jeffrey Smith, Alex Gunn, Megan Anakin \\ College of Education, University of Otago, Dunedin, New Zealand \\ Email: Jacques.vandermeer@otago.ac.nz
}

Received 10 February 2015; accepted 28 February 2015; published 3 March 2015

Copyright (C) 2015 by authors and Scientific Research Publishing Inc.

This work is licensed under the Creative Commons Attribution International License (CC BY). http://creativecommons.org/licenses/by/4.0/

(c) (i) Open Access

\begin{abstract}
Affordances of contemporary communications technology challenge the unquestioned assumptions and rationale of lectures. Furthermore, as students have changed their patterns of engagement with learning, universities have begun to reconsider their tradition of offering students lectures. These circumstances have prompted a group of teachers in one department to develop an alternative lectures: the bite-size mobile learning initiative. The initiative involved replacing some of the lectures with short video recordings of course material, "video-clips", that could be watched by students at their convenience then elaborated and used to stimulate discussions in subsequent tutorials. We found that close to one-half of all respondents agreed or strongly agreed that videovideo-clips worked as a learning tool, either alone or in combination with the tutorials; however, only $35 \%$ of respondents agreed or strongly agreed that they enjoyed watching the video-videoclips. The overwhelming majority of respondents agreed on one aspect: shorter is better.
\end{abstract}

\section{Keywords}

Undergraduate Teaching, Lecture Format, Mobile-Learning, Student Engagement, Video Recordings

\section{Introduction}

University teaching has come under the spotlight; it is now subject to the same level of concern as the compulsory education sector. Because of the rapid expansion of the higher education sector and the concomitant rise in public expenditure, the effectiveness of teaching in higher education has received increased scrutiny (reference). Concern for the quality of university teaching is evidenced by the staff development units that have been established, teaching and learning conferences that are common events, and performance measures related to teaching imposed on academic staff by internal and external quality assurance bodies (reference). Much of this attention 
is focused on the dominant form of teaching in many universities; the lecture. Even though lectures have been subjected to enhancement initiatives, they have largely remained unchallenged as a mode of teaching.

Over the past few decades, advances in communications technology have introduced new possibilities in the learning and teaching arena. The affordances of contemporary communication technology challenge the need and efficacy of the lecture mode of teaching (Weller, 2011). There are, however, equally strong detractors to "unseating" the lecture as the preferred mode of teaching in a mass education system. Arguments in support of the lecture are made in terms of its established track record (reference) as well as scale and affordability (reference). Given the debate about lectures, our challenge is to suggest an alternative that is defensible in terms of its pedagogical rationale, its ability to effectively address learning outcomes, and be practical and economically viable. We are not suggesting that there is no place for lectures in higher education. We are, instead, questioning the historical dominance of the lecture format given the affordances of current communications technology; including the role of the teacher in the learning process.

\subsection{Lectures}

There are two main concerns about the tradition of the lecture in higher education. The first concern is related to the transmission role of teachers in the lecture (reference). In this case, teachers interact with their students as "empty vessels" in which they pour their knowledge. At a later date, students are expected to reproduce that knowledge during a test. The second concern is related to the passive role of students in the traditional lecture (reference). Generally, students' active engagement during a lecture is confined to listening and note-taking. These two concerns point to an outmoded understanding of pedagogy on the part of the teacher.

In higher education, teachers have been challenged to become cognizant of how they can apply constructivist ideas in their practice (McGarr, 2009; Powell, 2003). Typically, universities provide teachers with academic staff development opportunities that aim to help them rethink their role as a transmitter and the role of their students' as receivers. Contemporary pedagogy in higher education has applied research findings from areas such as student engagement, information processing, and instructional design to improve teaching practice. For example, by using information about students' attention spans, teachers have included one or two brief rests called focus break in their 50 minute lectures (reference). From research about instructional design, teachers are thinking carefully about how they sequence course material and how to make more effective use of visual aids such as presentation slides (van der Meer, 2012). One important message from staff developers to teachers has been that what the student does during a lecture or tutorial session is more important than what they do (Biggs, 2003). These pedagogical innovations represent challenges to the way lectures are delivered and suggest that students benefit from changes in teaching practice.

Perhaps the concept of pedagogy itself needs to be questioned. The concept of andragogy suggests a different relationship between teachers and students (Knowles, 1970). Andragogy recognizes that university students are adults and that their relationships with their teachers will involve different dynamics than when teaching involves students who are children. In particular, andragogy focuses on students as self-directed and autonomous learners. The concept of andragogy does not address the role of knowledge in the teaching and learning relationship however, so teachers remain responsible prescribing the learning materials.

In contrast to andragogy, the concept of heutagogy may better expresses the contemporary relationships between students, knowledge, and teachers (Hase \& Kenyon, 2000, 2007; Kenyon \& Hase, 2001). Heutagogy expands a student's scope of self-determination in the learning process and includes formal and informal learning opportunities. Specifically, students should take a greater role in deciding what resources may be most useful to study to achieve a particular learning outcome rather than relying on their teacher to prescribe them. Teaching methods such as inquiry learning or problem-based learning offer opportunities for students take the initiative and challenge the pedagogical dynamics traditionally invoked during lectures (references).

By questioning assumptions about the role of the teacher, student, and knowledge in traditional lectures and by expanding the concept of pedagogy with features of andragogy and heutagogy, we have laid the groundwork for considering the role of technology on the teaching and learning environment in higher education.

\subsection{Technological Changes}

Developments in communications technology have had a considerable impact on the teaching and learning environment in higher education. Not only has the form of communication technology changed but their possible 
functions have suggested new teaching possibilities to innovators. For example, data projectors have replaced overhead projectors, which were once considered a revolutionary successor to the chalk board. Data projectors are now ubiquitous in university teaching areas and allow for presentations to include audio and video elements, in addition to images or text. Whereas lectures once provided the only access to the relevant information for a particular course, this is no longer the case. Students can now access digitised course materials and no longer need take verbatim notes as their only way to access lecture information (van der Meer, 2012). Learning management systems have succeeded printed documents as the source of course material and provide students with increased opportunities to access that material.

Learning management systems have increased the possible forms of material presented to students, but unlike data projectors, their function allows for greater accessibility. Students no longer have to rely on lecture delivery in a particular place and time and universities can operate with the principle of abundance rather than scarcity (Weller, 2011). With abundant content, teachers are free to adopt a role as a facilitator in the learning environment and guide students as they access course content through a range of technologies. Technology also allows students to make sense of the content by connecting with other learners, within and beyond their own institution, in addition to processing it themselves.

In many universities, including our own, lectures are routinely recorded and made available through the institution's learning management system (reference). Typically, other course materials used or created during the lecture, such as presentation slides or notes, are also made available to students. Learning management systems have also given students the opportunity to view lectures indirectly through video-linking to accommodate large class sizes that exceed lecture hall capacity or to allow for the delivery of a course at multiple campuses by a single lecturer.

In addition to learning management systems, easy access to information by the Internet to the World Wide Web offers possibilities to change the role of lectures and alter the relationship between lecturers and students. For example, information storage and sharing has been revolutionised with the dynamic, user-generated, collaborative affordances of Web 2.0 tools. One innovative use of the Internet and the World Wide Web has been establishment of the website www.khanacademy.org by Salman Khan in 2006. The website features a range of learning resources including short video recordings so that anyone, anywhere can access them. These tools have added to the ways students can engage with learning by further democratising access to information and knowledge from the static confines of textbooks.

The technological developments outlined above have prompted us to consider whether traditional lectures are still relevant for the second decade of the $21^{\text {st }}$ century. Our response to the debate about lectures and possibilities offered by technology has been to explore the ways we could replace lectures with mobile bite-size learning.

\subsection{Mobile Bite-Size Learning}

As in most universities, lectures are standard part of the variety of teaching approaches in our university. In our particular faculty, lectures in a number of courses are broadcast with live video transmitted from the main campus to a small remote campus. When lectures are streamed, opportunities for interaction between teachers and students are limited by the video link, therefore, teachers tend to focus on delivery of course material. The limitations imposed by streamed lectures provided the impetus to explore how we could enhance the learning experience of students. The short video recordings made by the Kahn Academy provided us with one possible solution and data collected from students' about their learning experiences with recorded lectures in other courses at our university indicated that they preferred video recordings showing the slide presentation and the teacher talking at the same time (reference). Our initiative involved using mobile communications technology to deliver course content to students that was traditionally delivered to them via the lecture.

Video recordings, were a critical component of the mobile bite-size learning initiative, therefore we report on three features of the video-clips, used in our pilot project. The features we evaluated involved students reporting their perceptions of the video-clips in place of lectures and involve three research questions. First, did our students appreciate the video-clips we produced? Second, how did our students incorporate the video-clip into their study habits? Third, what were our students' preferences for different aspects of the video-clips?

\section{Methods}

To implement our mobile bite-size learning initiative, we specified the three design requirements for our pilot 
project. First, the 50-minute lecture must be replaced with 2 - 4 shorter or "bite-sized" video-clips. In this way, conventional lecture material, typically presented through use of presentation slides, was re-packaged in shorter segments and video recorded by teachers as mini-lectures. Second, the location and time for viewing the recordings must be flexible. Flexibility required that the recordings were formatted to allow them to be accessible on any mobile device owned by a student. Third, students' preferences were included, such as the traditional visual presentation of the lecture along with the talking head of the teacher.

To create the video-clips, we used screen capture software from www.screencast-o-matic.com because it was freely available and functioned on all of our devices as long as they had internet access, a microphone, and a video camera. After each video-clip was made it was saved in MP4 format and then uploaded to our learning management system.

The teaching teams of three undergraduate courses at the 100-level, 200-level, or 300-level of study were involved in the mobile bite-size learning initiative. Teaching teams consisted of 8, 6, and 1 members, including a course coordinator, for each course at the 100-level, 200-level, or 300-level of study respectively. Course coordinators were provided with the three design requirements and encouraged to implement their interpretation of mobile bite-size learning. Because this was the pilot stage of the initiative, there was no particular format prescribed therefore, the three course coordinators developed their own approaches. Typically, the visual layout consisted of a presentation slide filling the screen with smaller image of a teacher's talking head placed in one corner.

Because the 100- and 200-level courses were taught by teams, the video-clips produced by those teams had greater variability than the recordings produced by the sole teacher of the 300-level course. Experience working with the video recording software differed amongst the members of each teaching team therefore the video-clips varied in quality of visual layout and audio volume in addition to duration. For example, less experienced teachers did not realise that they needed to edit their slides to account for the presence of their talking head that obstructed parts of the images and text used in the slides.

Not all lectures in each thirteen-week course were replaced by video-clips. There were three and four lectures were held in the 100- and 200-level courses, respectively. The 100- and 200-level courses had two-hour workshops for groups of up to 28 students weekly.

At the end of the thirteen-week semester, students were invited to fill in a survey about their learning environment. The survey items were designed to gather information about students' use, appreciation, and preferences of the video-clips as well as study behaviour, and other aspects of the course, such as the workshops and workload. The range of items was used to put students' responses about the mobile bite-size learning initiative into the context of their other course-related study experiences.

The surveys were administered in two ways. For the 100-level course, the survey was administered to all students in the course during in the last week of the semester at a final lecture. For the 200- and 300-level courses, the survey was administered during the final workshop class of each course.

Twenty-six of the 37 questions were Likert-scale questions and they are shown in Table 1. Seven questions gathered information about study habits, video-clip usage and preferences, course workload, and demographics. Data generated from the 33 questions were analysed using descriptive statistics, an exploratory factor analysis to identify reliable factors, and analysis of variance to identify the significant characteristics of students' responses to the three research questions.

Four questions were open-ended and were designed to provide opportunities to gather further insights into students' appreciation of the mobile bite-size learning initiative. The three open-ended questions were "What about the videos has been most helpful/effective?", "What suggestions could you make to further enhance the mixed-mode of delivery (workshops/video-video-clips) in the course?”, "What would you advise a student who takes this course next year about how to make the most of the video video-clips?”, and “Anything else you would like to communicate to the course coordinator(s)?” Students' responses to the open-ended questions were used to illustrate the quantitative results.

\section{Results}

Of the total number of students enrolled in the three courses $(\mathrm{N}=653), 437$ students filled in the survey. Overall, the response rate was $67 \%$. There were no major differences between response rates in the three courses, with $67 \%$, 65\%, and 71\% in the 100-, 200-, and 300-level courses, respectively. Not all respondents answered all 
Table 1. Question descriptive.

\begin{tabular}{|c|c|c|c|c|c|}
\hline Question & $\mathbf{N}$ & Min & Max & Mean & Std. Dev \\
\hline Q1_The workshops/tutorials were the best thing for me about this course & 432 & 1 & 5 & 3.81 & 1.14 \\
\hline Q2_I enjoyed watching the video-clips made by the teachers & 435 & 1 & 5 & 2.99 & 1.15 \\
\hline Q3_At times I watched and discussed the video-clips with fellow students & 435 & 1 & 5 & 2.3 & 1.15 \\
\hline Q4_I feel I worked hard to get ready for workshops & 435 & 1 & 5 & 2.93 & 1.03 \\
\hline Q5_The video-clips do not work for me as a learning tool. & 435 & 1 & 5 & 2.78 & 1.36 \\
\hline Q6_The workshops stimulated my interest in the topic & 433 & 1 & 5 & 3.69 & 1.04 \\
\hline Q7_The workshop/tutorial formats overall worked very well for me. & 432 & 1 & 5 & 3.61 & 1.07 \\
\hline Q8_I prefer having access to video-clips over attending lectures & 433 & 1 & 5 & 2.79 & 1.49 \\
\hline Q9_I read all the material each week & 434 & 1 & 5 & 2.59 & 1.07 \\
\hline Q10_I prefer more shorter video-clips, to fewer longer video-clips & 433 & 1 & 5 & 3.73 & 1.21 \\
\hline Q11_There should be more action/activities in the video-clips & 431 & 1 & 5 & 3.1 & 1.00 \\
\hline Q12_I like the format of a video clip with one person talking with presentation slides & 433 & 1 & 5 & 3.46 & 1.22 \\
\hline Q13_I watched some video-clips more than once to enhance my learning & 434 & 1 & 5 & 3.12 & 1.35 \\
\hline Q14_I liked the overall learning environment in this course & 434 & 1 & 5 & 3.38 & 1.16 \\
\hline Q15_Having the presentation slides to print out beforehand is helpful & 423 & 1 & 5 & 3.99 & 1.11 \\
\hline Q16_I would definitely recommend this course to other students & 430 & 1 & 5 & 3.45 & 1.03 \\
\hline Q17_I prefer video-clips to start with a brief overview of what will be covered & 428 & 1 & 5 & 3.69 & 1.10 \\
\hline $\begin{array}{l}\text { Q18_The relationships between the video-clips and other class activities were not } \\
\text { always apparent to me }\end{array}$ & 429 & 1 & 5 & 2.96 & 1.07 \\
\hline Q19_The amount of work we were asked to do in this course was about right & 425 & 1 & 5 & 3.11 & 1.14 \\
\hline Q20_I would like more courses to use video-clips and have fewer or no lectures & 428 & 1 & 5 & 2.55 & 1.43 \\
\hline Q21_I participated actively in the workshops & 429 & 1 & 5 & 4.02 & .89 \\
\hline Q22_I made notes as I watched the video-clips & 430 & 1 & 5 & 4 & 1.12 \\
\hline Q23_The combination of workshops/tutorials and video-clips worked very well for me & 426 & 1 & 5 & 3.34 & 1.16 \\
\hline Q24_The video-clips worked to develop my interest in the course topics & 429 & 1 & 5 & 3.1 & 1.20 \\
\hline $\begin{array}{l}\text { Q25_There were clear relationships between the video-clip content and other course } \\
\text { activities }\end{array}$ & 430 & 1 & 5 & 3.34 & .95 \\
\hline Q26_I watched all the video-clips & 427 & 1 & 5 & 3.17 & 1.47 \\
\hline
\end{tabular}

questions. The results will be reported in three sections: students' appreciation, study habits, and preferences of the video-clips.

\subsection{Students' Appreciation of the Video-Clips}

Table 1 shows the descriptive statistics of the Likert-scale items (strongly disagree 5, strongly agree 5). The two negatively-worded questions 5 and 18 were subsequently reverse-coded.

A few results stand out in the responses to individual questions specifically related to video-clips. Students seemed moderately satisfied with the video-clips, but not overwhelmingly so. Responses to the question of the combination of workshops and video-clips revealed more positive results. Combining the disagree and agree scores for the three main video-clip related questions, as displayed in Figure 1, suggests a three-way split for students enjoying watching the video-clips, and close to half of the students considering the video-clips as contributing to their learning in some respect.

To better understand the relationship between the questions and reduce the variables to a smaller set of variables that reflect the different dimensions, we performed factor analysis (principal component, varimax rotation). We performed two separate analyses, one incorporating the fourteen questions related to students' perceptions and experiences of the value of the learning environment, and another one for the six questions related to their 


\section{- (Strongly) disagree $\quad$ Neutral $\quad$ (Strongly)agree}

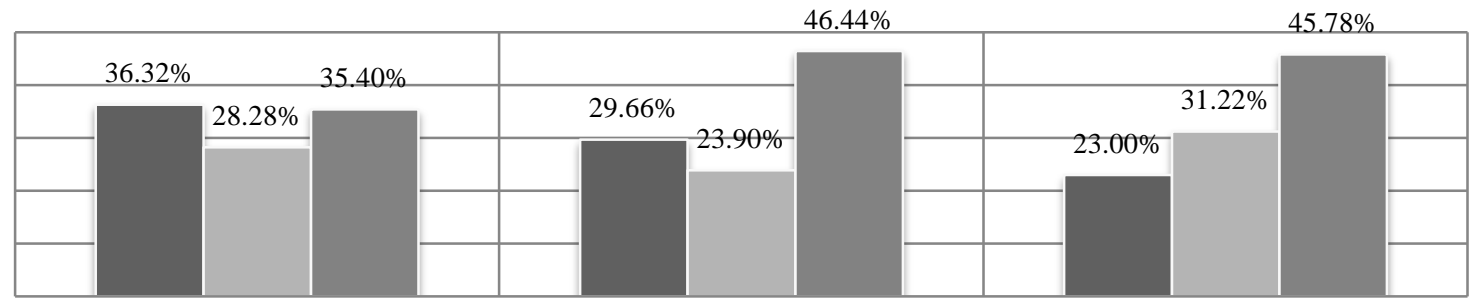

I enjoyed watching the video clips

the video clips worked as learning tool the combination video clips and workshop worked well

\section{Figure 1. Frequency distribution video-clip questions.}

study behaviour and efforts. For the first group of questions, this yielded three components, see Table 2. These could be characterized as describing respectively students' appreciation related to video-clips, workshops and relationship between video-clips and workshops.

The second component seemed to consist of two distinct dimensions, the first three questions were directly related to the workshops, the second two related to overall judgment of the course. For the subsequent calculation of reliability scores, we separated these two. Table 3 shows the reliability scores for the four scales we created. It is generally accepted that .7 is the lower boundary for acceptable reliability. The first three scales, then, can be considered as reflecting to an acceptable degree the common dimension of the underlying individual items.

The results suggest that students seemed moderately satisfied with the use of the video-clips, with some modest differences between year levels. In considering the relationship between these scales, we established a strong correlation $(r=.532)$ between students' appreciation of video-clips and their overall evaluation of the course. This could suggest that for students the video-clips may have played a more important role in how they felt about their overall experience of the course. This was slightly less so for workshops $(r=.485)$ and the relationship between these two $(r=.455)$.

The relationship between students' appreciation of video-clips and their overall evaluation of the course was less strong for the 100-level course $(r=.355)$ and stronger for the 200 and 300 level courses $(r=.697$ and $r=.606)$.

Another difference in appreciation related to students' perception of difficulty of the course. There was a significant difference in the scores for students who considered their course to be "about right" $(M=3.07, S D=.99)$ and those who found it "too hard" or "too easy" $(M=2.70, S D=1.00) ; t(409)=3.27, p=0.001$.

Although students at the remote campus $(M=3.10, n=116)$ reported higher appreciation levels with the video-clips than the main campus-based students $(M=2.94, n=314)$, this was not significant $(p=.198)$. There were also no significant gender differences $(p=.061)$.

From the open-ended questions, students indicated that what they found most helpful was the flexibility that the video-clips afforded them, being able to watch them anytime, anyplace, stop/start/rewind, and being able to make notes at their speed. Furthermore, they appreciated that the video-clips provided them with a better understanding of the course material: an introduction to the reading, a summary and an overview of the material; some indicated that the video-clips were easier than doing the readings. However, some also indicated that they did not appreciate and that they had not signed up for an e-learning course and that they preferred lectures. In Table 4 are some illustrative examples of these main response groups.

\subsection{Students' Study Habits with the Video-Clips}

In this section we will report on the results for the questions that sought to understand students study habits. The assumption was students' appreciation of the use of video-clips may have a relationship with their overall approach to their studies. In other words, we assumed that those students who make an effort to prepare for workshops, complete their readings and watch the video-clips, would be better placed to judge their experience with the video-clips. Table 5 shows that the second factor analysis revealed two components.

We then analysed the relationship between the four scales that yielded satisfactory reliability. The results in 
Table 2. Rotated Component Matrix related to questions of perceptions and experiences of the value of using video-clips.

\begin{tabular}{|c|c|c|c|}
\hline \multirow{2}{*}{ Question } & \multicolumn{3}{|c|}{ Component } \\
\hline & 1 & 2 & 3 \\
\hline Q20_I would like more courses to use video-clips and have fewer or no lectures & .832 & .044 & -.076 \\
\hline Q8_I prefer having access to video-clips over attending lectures & .823 & .014 & -.067 \\
\hline Q24_The video-clips worked to develop my interest in the course topics & .758 & .087 & .318 \\
\hline Q23_The combination of workshops/tutorials and video-clips worked very well for me & .691 & .296 & .323 \\
\hline Q2_I enjoyed watching the video-clips made by the teachers & .687 & .044 & .383 \\
\hline Q5R_the video-clips did work for me as a learning tool & .670 & -.047 & .209 \\
\hline Q1_The workshops/tutorials were the best thing for me about this course & -.035 & .848 & -.010 \\
\hline Q7_The workshop/tutorial formats overall worked very well for me. & .066 & .842 & .130 \\
\hline Q6_The workshops stimulated my interest in the topic & -.033 & .842 & .108 \\
\hline Q16_I would definitely recommend this course to other students & .368 & .529 & .342 \\
\hline Q14_I liked the overall learning environment in this course & .487 & .527 & .244 \\
\hline Q18R_the relationship between video-clips and other class activities was clear & .013 & .076 & .767 \\
\hline Q25_There were clear relationships between the video-clip content and other course activities & .482 & .121 & .616 \\
\hline Q19_The amount of work we were asked to do in this course was about right & .129 & .135 & .525 \\
\hline
\end{tabular}

Table 3. Scale descriptive.

\begin{tabular}{|c|c|c|c|c|c|c|}
\hline Factors & Cronbach $\alpha$ & Number of items & Mean all respondents & 100-level & 200-level & 300-level \\
\hline Video-clip appreciation & .87 & 6 & 3.00 & 3.11 & 2.87 & 2.84 \\
\hline Workshop appreciation & .84 & 3 & 3.70 & 3.79 & 3.80 & 3.10 \\
\hline Overall judgment & .72 & 2 & 3.41 & 3.51 & 3.43 & 2.96 \\
\hline Relationship video-clips/workshops & .52 & 3 & 3.17 & 3.15 & 3.19 & 3.16 \\
\hline
\end{tabular}

Table 4. Response to the question: “What about the videos has been most helpful/effective?”.

\section{Illustrative comments}

- Being able to pause the videos and go back if I didn’t understand something. Without a doubt the videos were great in highlighting important concepts as I often struggle to know what points are important. They created a format of the overall topic and the subtopic.

- Can do them when you are motivated to when it suits you to do them. Can go back to them.

- Easier to understand than the books, reading material.

- Gives me an idea about what is important in one course so I can prepare effectively for workshops. (also makes it more personal)

- I enjoyed the fact if you didn't understand something you could click on it and review it over and over until you did.

- Using them to refer back to when doing an assignment and clarifying ideas. Also using quotes for referencing.

- You can watch anywhere with an internet connection.

- Start doing some actual teaching to students, not teaching/talking to a video camera. I paid good money for this course.

- I did not enjoy the video video-clips. The course became an online course, something I did not sign up for. I felt the online video-clips were handy for the professors, however as for me I would have enjoyed coming to class and learning in a physical setting

Table 5. Rotated Component Matrix related to questions of effort and behaviour.

\begin{tabular}{lcc}
\hline & \multicolumn{1}{c}{ Components } \\
\cline { 2 - 3 } & $\mathbf{1}$ \\
Q4_I feel I worked hard to get ready for workshops & .848 & .127 \\
Q9_I read all the material each week & .846 & .580 \\
Q26_I watched all the video-clips & .320 \\
Q21_I participated actively in the workshops & .040 \\
Q3_At times I watched and discussed the video-clips with fellow students & .005 \\
Q13_I watched some video-clips more than once to enhance my learning & .780 \\
\hline
\end{tabular}


Table 6 suggest that there is some relationship between their appreciation of the use of video-clips and their overall appreciation of the course, as well as their self-reported effort.

Two open-ended questions were asked about the weekly time respondents spent on their course readings and video-clip watching. Interestingly, many respondents did not complete these two questions, especially in relation to watching the video-clips. Possibly they found it difficult to estimate the time spent. Further analysis showed some difference by course level. The difference between the number of missing values for the video watching question in particular were noted, $11 \%, 17.6 \%$ and $38.6 \%$ respectively for the 100,200 and 300 -level courses. There was also a difference in average weekly reading times: $2.13,2.10$, and 1.71 respectively, for the three course levels, and 1.53, 1.51, and 1.14 for the average watching times. These differences, however, were not significant.

Table 7 suggests that most students watched the video-clips one time only. This finding was confirmed by another question related to student viewing patterns, where only $7 \%$ of students indicated that they watched the video-clips more than once during the week. However, one-third of all respondents indicated that they watched the video-clips later to revise for a test, assignment, or exam. Year level differences were found also in these responses, with $31 \%$ students in the 100 -level course indicating this behaviour, $45 \%$ of 200 -level, and only $12 \%$ in the 300-level course.

Responses to the open-ended question about the advice respondents would give to future students using the video-clips, gave us insight into that habits of students, or at least the study habits that they considered desirable even if they had not observed these habits. The most dominant themes were the desirability to keep up with watching the video-clips each week, to make notes and to watch them more than once for understanding, revision or assignment preparation. One student recommended to download the video c recordings lips automatically by using the rich site summary (RSS) feature afforded by our learning management system. Table 8 provides some selected examples of advice given by respondents.

\subsection{Students' Preferences the Video-Clips}

Respondents were presented with a number of options with regards to the image composition of the video-clips: just the face of the lecturer, just the slide presentation, both at the same time, face and slide presentation alternating, face with every now and then slide presentation or diagram. The majority of respondents, $67 \%$, preferred to have the slide presentation and face of the lecturer at the same time.

On the other hand, students seemed less certain about the degree of "activities" to be included in the videoclips. Under $32 \%$ were affirmative, whilst $46 \%$ responded neutral. However, they may not have been entirely certain what was meant by the question or what activities were referred to. An example of what was meant may have been useful—such as the lecturer encouraging students to pause at different points to consider a question or discuss a question with another student before resuming viewing of the video-clip.

To the question whether students liked video-clips to start with a brief overview of what was going to be covered, $61 \%$ of students responded in the affirmative, with another $25 \%$ indicating a more neutral response.

Students were also clear about the preferred length of the video-clips. Table 9 shows that most students preferred the video-clips to be relatively short: $83 \%$ of the total sample preferred the video-clips to be no longer than fifteen minutes. However, there were some differences between year levels. Whereas $91 \%$ students of the 100 -level course preferred the video-clips to be no longer than 15 minutes, for the 200-level course this was $81 \%$ and for the 300 -level course $54 \%$.

The open-ended question with regards to suggested improvements also gave us an insight into students' preferences. The selection of comments in Table 10 provides an illustration of the range of comments.

\section{Discussion}

Overall, students' satisfaction with this pilot project seemed moderately positive. The levels of satisfaction with the video-clips were positively related to their overall satisfaction with the course. However, this was less strong for the 100-level course. It is difficult to interpret these results with any certainty. However, the three courses were not uniformly designed and it would be difficult to establish whether the differences were related to students' expectations, or the design features.

The majority of respondents preferred to have the slide presentation and the face of the lecturer at the same time. This was the format of the video-clips students had access to. Familiarity with this format may have 
Table 6. Correlations between the fours scales with satisfactory reliability.

\begin{tabular}{cccc}
\hline & Video Clip appreciation & Effort & Workshops appreciation \\
\hline Video Clip appreciation & 1 & & \\
Effort & .387 & 1 & .194 \\
Workshops appreciation & .129 & .336 & 1 \\
Overall judgment & .548 & .485 \\
\hline
\end{tabular}

Correlations all significant at the 0.01 level (2-tailed)

Table 7. Amount of time respondents spent on reading and watching per week.

\begin{tabular}{cccc}
\hline Time spent & Reading \% & Watching \% & 5.8 \\
\hline Not at all & 4.6 & 36.0 & 60.6 \\
1 hour & 33.0 & 21.2 & 7.2 \\
2 hours & 10.9 & 2.2 \\
3 hours & 5.3 & 10.2 & 3.0 \\
\hline
\end{tabular}

Table 8. Response to the question "What would you advise a student who takes this course next year about how to make the most of the video clips?”.

\section{Illustrative comments}

- Repetition is the mother of all skill. Watch them over and over, it really helps to get it into your head.

- Definitely download them and revisit them before studying for an exam. Often when you go straight to the textbook it can be quite overwhelming and this makes you feel like you don't know anything, however videos refresh your memory.

- Do the reading watch the video clip and take notes then just watch it again to make sure it all went in.

- Keep up to date with the podcast. Readings - do all of it before class, so you can participate in class (workshop)

- Get a group together and watch the video-clips in a room together.

- Keep pausing the video video-clips so you understand everything the lecturer is saying

- Take notes as you watch the video clip

- Make the time each week to watch. Be consistent and create a routine.

Table 9. Amount of time respondents spent on reading and watching per week.

\begin{tabular}{ccc}
\hline Preferred length & $\%$ & 27.8 \\
\hline $1-9$ minutes & 54.6 & 9.3 \\
$10-15$ minutes & 8.3 \\
$16-20$ minutes & & \\
\hline
\end{tabular}

Table 10. Response to the question: "What suggestions could you make to further enhance the mixed-mode of delivery (workshops/video-clips) in the course?”.

\section{Illustrative comments}

- Video-clips shorter and more exciting.

- Connect information given in power points/videos to information given in workshops.

- Have video video-clips available over the weekend prior to workshop as I found it easier to make sense of the readings after watching them.

- Having the workshops and video video-clips really linked. i.e. going over video video-clips and readings in the workshops to make sure we understand them.

- Shorter video-clips - don’t mind if there was more just a pain to load and to pause. Loved the workshops - less readings!

- Some formative assessment each week based on podcast readings.

- Starter video-clips with more, interesting approaches. The students are on laptops Facebook is a click away. 
prompted their response. Our choice for this format was informed by indications of this preference in another course within our university. What the reason is for this preference is not known and cannot be established from the data in the survey. Future research may well want to enquire into this.

What seems very clear, however, is that a majority of students were in favour of brevity, more so the firstyear students than later year students. One question that comes to mind is whether this relates to some extent to the age of the students and their greater familiarity with brief internet video-clips, such as those found on YouTube. We did not ask students to indicate their age but would be useful to include in a future survey.

Overall then, this pilot in three different courses at three different year levels with no common design structure seems to suggest some considerations as to the preferred format for video-clips. The variability of design and delivery present a clear limitation to this study. Future research into this area would benefit from a more structured approach in designing video-clips. Evaluation of this first pilot will benefit the design of a second pilot.

More in-depth systematic analysis will also be carried out with regards to the open-text comments that we elicited; these may reveal more areas for attention in designing a follow-up stage-two pilot. A follow up pilot project will investigate how the time freed up by lectures could be used to develop more structured approaches students' productive use of time in processing video-clip material and related readings prior to coming to the workshops. This could take the format, for example, of guided peer-learning groups.

\section{Conclusion}

The aim of this project was to gain an understanding of students' perception of the changes we made in the course delivery. This foray into using an alternative to traditional lecture delivery was just a first start in exploring different technologies as a result of technological affordances and a desire to identify a range of effective teaching/learning approaches. The findings of this study may inform other higher education teachers who are considering using short video-clip to replace some (or all) of their lecture material. The clear message we received from students was that the video-clips should not try to "mimic" traditional lectures by making these too long. One of the perceived benefits of video-clips is their brevity. The key message, therefore, is: "shorter is better".

\section{References}

Biggs, J. (2003). Teaching for Quality Learning at University: What the Student Does (2nd ed.). Buckingham: SRHE and OUP.

Hase, S., \& Kenyon, C. (2000). From Andragogy to Heutagogy. Ultibase Articles, 5, 1-10.

Hase, S., \& Kenyon, C. (2007). Heutagogy: A Child of Complexity Theory. Complicity: An International Journal of Complexity and Education, 4, 111-118.

Kenyon, C., \& Hase, S. (2001). Moving from Andragogy to Heutagogy in Vocational Education. Paper presented at the Proceedings of the Australian Vocational Education and Training Research Association Conference (4th, Adelaide, Australia, 28-30 March). ERIC Document.

Knowles, M. S. (1970). The Modern Practice of Adult Education (Vol. 41). New York: New York Association Press.

McGarr, O. (2009). A Review of Podcasting in Higher Education: Its Influence on the Traditional Lecture. Australasian Journal of Educational Technology, 25, 309-321. http://www.ascilite.org.au/ajet/ajet25/mcgarr.html

Powell, K. (2003). Science Education: Spare Me the Lecture. http://search.proquest.com/docview/73666518?accountid=14700

van der Meer, J. (2012). Students' Note-Taking Challenges in the Twenty-First Century: Considerations for Teachers and Academic Staff Developers. Teaching in Higher Education, 17, 13-23. http://dx.doi.org/10.1080/13562517.2011.590974

Weller, M. (2011). A Pedagogy of Abundance. Spanish Journal of Pedagogy, 249, 223-236. 